\title{
Keratomycosis caused by Acremonium Recifei, treated with keratoplasty, Miconazole and Ketoconazole
}

\author{
H.J. SIMONSZ \\ Department of Ophthalmology, Amsterdam University Medical Centre, Meibergdreef 9, \\ $1105 \mathrm{AZ}$ Amsterdam, The Netherlands
}

Key words: mycoses, corneal ulcer, fungostatic antibiotics

\begin{abstract}
A patient is discussed who developed a fungal corneal ulcer due to Acremonium (Cephalosporium) Recifei after a piece of a coconut flew into his eye while he was cracking it. Treatment consisted of keratoplasty, Miconazole as ointment and intravenously, and Ketaconazole orally. Diagnosis and treatment of fungal corneal ulcers are discussed briefly.
\end{abstract}

\section{Introduction}

A 48-year-old man was seen at the Outpatient Department of the Wilhelmina Gasthuis on February 2nd, 1982, with a corneal ulcer of his left eye. While cracking a coconut with a hammer two months previously, a piece of the coconut had flown into his left eye. The referring ophthalmologist had removed the piece from the corneal stroma and prescribed Polymyxin B, Neomycin and Gramicidin eyedrops and Atropine eyedrops. As the ulcer did not heal the patient was referred to this hospital. On examination visual acuity was $5 / 5$ in the right eye and $1 / 10$ in the left eye. A $3 \mathrm{~mm}$ corneal ulcer with crenated border was seen in the left eye with oedema, an immune ring surrounding the ulcer and a streak of matter arising from the endothelium behind the ulcer. Cells and flare were noted in the anterior chamber. A biopsy yielded fungi and Pimaricin eyedrops were prescribed. Initially the cornea cleared but after a few weeks hypopyon developed; Miconazole ointment was tried for a short while but discontinued because of severe pain, which was relieved with Dexamethasone eyedrops.

Because of relentless progression of the ulcer and threatening perforation, the patient was admitted to hospital on April 13th, 1982. Treatment was started with a 45 -minute intravenous infusion of $600 \mathrm{mg}$ Miconazole twice daily and $1 \%$ Miconazole ointment four times daily. On April 15th, a penetrating keratoplasty was performed. The culture taken from the biopsy yielded Acremonium (Cephalosporium) Recifei with the following sensitivity, expressed as minimal inhibitory concentrations in $\mathrm{mg} / \mathrm{l}$ : Econazole: $\frac{1}{2}$, Miconazole: 1, Clotrimazole: 2, Pimaricin: 4, Amphotericin B: 8, Ketoconazole: 16, Nystatin: 32, Griseofulvin: 32, Flucytosine: more than 64. On leaving 
hospital the visual acuity was $1 / 10$ and the transplant was almost clear. Posterior synechiae had developed. Oral Ketoconazole, $200 \mathrm{mg}$ twice daily, was substituted for Miconazole and continued for three months. As no corticosteroids were given, the transplant soon became opaque. A second penetrating keratoplasty and synechiolysis were performed in September 1983. Vision is now 0.40 .

\section{Discussion}

Leber described the first case of fungal corneal ulcer in 1879 in a farmer who got oat chaff in the eye while threshing. There are no figures on the incidence of fungal corneal ulcers in The Netherlands. In the USA the rate is estimated at 300 cases yearly (DB Jones, 1982). The incidence is assumed to have risen under the influence of the use of antibiotics and corticosteroids (BR Jones, 1975). A study from the Armed Forces Institute of Pathology (Naumann et al., 1967) yielded 3 cases in 34000 enucleations between 1933 and 1951 , but 48 cases in 15000 enucleations between 1952 and 1966 . The prevailing causative organism in Europe is Aspergillus, in the USA it is Fusarium (BR Jones, 1975). Acremonium Recifei (formerly called Cephalosporium Recifei) is a tropical fungus living on plants in Africa and South America. Rarely, mycetomata of the feet have been reported (Gams, personal communication). In 133 cases, predisposing factors were analysed by Liesegang and Forster (1980)

$82 \%$ were men,

$60 \%$ sustained corneal trauma, in most cases with vegetable matter, (note that fungi do not contain chlorophyll, so they live on vegetable matter only)

$25 \%$ received corticosteroid drops before referral,

$18 \%$ had a general illness,

$6 \%$ had had a previous corneal infection,

$2 \%$ received corticosteroids before the development of the ulcer, and

$2 \%$ wore contact lenses.

Fungi are ubiquitous. Fungi were cultivated from the conjunctiva in $6.6 \%$ of a series of 664 healthy eyes (453 patients) (Ando, 1982). In 22 out of 312 cases of HEMA soft contact lens intolerance, fungi were cultivated from the lenses (Neuhann et al., 1978). Some contact lens cleaners could not even kill the fungi.

BR Jones (1975) described the following characteristics of fungal corneal ulcers: (1) indolent, recrudescent course; (2) dry, crumbly raised surface to a white or yellow ulceration; (3) crenated edge; (4) finger-like extensions into the stroma; (5) satellite lesions; (6) recurrent hypopyon; and (7) ring of immunecomplex deposits surrounding the ulcer.

As complications he has noted: (1) corneal scar; (2) cataract; (3) perforation; and (4) seclusio with the iris plastered onto the lens, as fungi have a predilection for growing in the posterior chamber. 


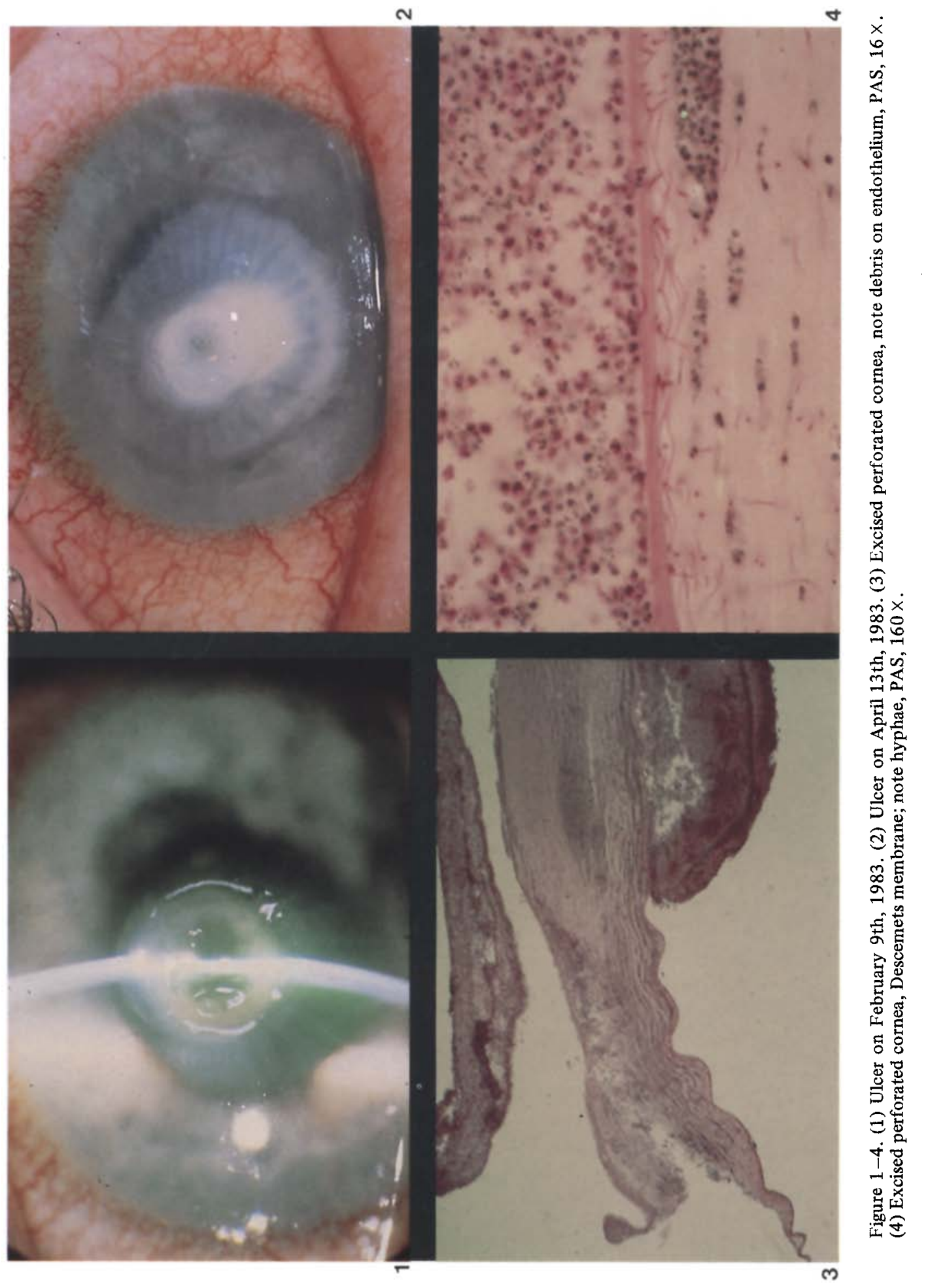


Diagnosis is established by: (1) direct visualisation of hyphae with slitlamp $(40 \times)$; (2) staining biopsy material with: Gram, Giemsa, Grocott methanamine silver (Liesegang and Forster, 1980). It is not advisable to use $\mathrm{KOH}$, otherwise necessary for dissolving the keratin of the skin. (3) Culture with: Sabouraud agar, blood agar, brain/heart suspension, at 25 and 37 degrees, preferably with the use of a rotating shaker, which reduces the time of culture to about 2 weeks (O'Day et al., 1979).

In The Netherlands determination of the fungus can be carried out at the Schimmelinstituut in Baarn and sensitivity to antibiotics can be assessed at the Rijks Instituut voor de Volksgezondheid in Bilthoven and at Janssen Pharmaceutica in Beerse (Belgium). Innoculation on plates with antibiotics is not a suitable method for determining sensitivity as great variability results from differing inoculum size and differing media (Roberts, 1982).

Therapy consists primarily of treatment with one of the following antibiotics: (1) polyene antibiotics: Amphotericin B, intravenously, Nystatin, as eyedrop or ointment, Pimaricin, as eyedrop or ointment; (2) imidazole antibiotics: Clotrimazole, as eyedrop or ointment, Miconazole, as eyedrop, ointment or intravenously, Econazole, as eyedrop or ointment, Ketoconazole, orally; and (3) 5-Flucytosine, for Candida in particular, orally.

The choice of antibiotics should be governed by sensitivity tests, especially as different strains of one fungus species may vary greatly in their susceptibility to antibiotics. But even when the speed of culturing is enhanced by rotating shaking, it will still take about two weeks (O'Day et al., 1979). While awaiting the results of culture, one can use a systemic imidazole antibiotic plus $1 \%$ Miconazole as eyedrop or ointment plus $10 \mathrm{mg}$ Miconazole subconjunctivally every day, as proposed by Foster (1981). We would be reluctant to use Amphotericin B unless indicated by culture and sensitivity tests. Amphotericin B eyedrops, used in experimental rabbit corneal erosions, actually delayed closure of the epithelial defect, in contrast to other polyene and imidazole antibiotics (Foster et al., 1981). Pimaricin does not penetrate the corneal well, so it is best suited for superficial ulcers (BR Jones, 1975). Experiments on rabbits using Miconazole showed that this substance, administered as ointment, subconjunctival injection or intravenously, penetrated well into the anterior chamber and cornea. Only the subconjunctival injection however, accomplished some minimal penetration into the vitreous (Foster and Stefanyszyn, 1979). Other experiments in rabbits with Ketoconazole given orally yielded similar results, i.e. almost no penetration in the vitreous and good penetration in the cornea and anterior chamber (Chu et al., 1979). The blood/vitreous barrier however, may behave differently during inflammation. It is importance to realize that warmth is also deleterious to the fungus. Most fungi (not Candida) grow best at 25 degrees Celsius. The cornea reaches this temperature when exposed to wind, force Beaufort 3 , at an outside temperature of 18 degrees Celsius (Freeman and Fatt, 1973). So patients, while out of doors, should keep the affected eye well covered. 


\section{References}

Ando $\mathrm{N}$ and Takatori K (1982) Fungal flora of the conjunctival sac. Amer J Ophthal 94:67-74

Chu W, Forster CS, Moran K and Giovanoni R (1979) Intraocular penetration of ketoconazole in rabbits. Invest Ophthal Vis Sci ARVO Suppl 18:133

Foster CS and Stefanyszyn M (1979) Intraocular penetration of miconazole in rabbits. Arch Ophthal 97:1703-1706

Foster CS, Lass JH, Moran-Wallace K and Giovanoni R (1981) Ocular toxity of topical antifungal agents. Arch Ophthal 99:1081-1084

Foster CS (1981) Miconazole therapy for keratomycosis. Amer J Ophthal 91:622-629

Freeman RD and Fatt I (1973) Environmental influences on ocular temperature. Invest Ophthal 12:596-602

Jones BR (1975) Principles in the management of oculomycosis. Trans Am Ac Ophthal Otol 79:15-53

Jones DB (1981) Fungal keratitis In: Clinical Ophthalmology, ed: TD Duane, vol 4 chapter 21. Philadelphia, Harper and Row

Leber T (1879) Keratomycosis aspergillina als Ursache von Hypopyonkeratitis. Graefes Arch Ophthal 25:285-301

Liesegang TJ and Forster RK (1980) Spectrum of microbial keratitis in South Florida. Amer J Ophthal 90:38-47

Naumann G, Green WR and Zimmerman LE (1967) Mycotic keratitis, a histopathologic study of 73 cases. Amer J Ophthal 64:668-682

Neuhann T, Blassmann K and Roth HW (1978) Pilzwachstum auf weichen Kontaktlinsen. Klin Mb1 Augenheilk 173:648-653

O'Day DM, Akrabawi PL, Head WS and Ratner HB (1979) Laboratory isolation techniques in human and experimental fungal infections. Amer J Ophthal 87:688-693

Roberts DT (1982) The current status of systemic antifungal agents. Brit J Derm 106: $597-602$ 